\title{
Echocardiography in the Intensive Care Unit
}

\author{
Rebecca E. Burk ${ }^{1,2,3}$ • Sarah J. Beesley ${ }^{1,2,3}$ • Colin K. Grissom ${ }^{1,2,3}$ • \\ Eliotte L. Hirshberg ${ }^{1,2,3,4}$ • Michael J. Lanspa ${ }^{1,2,3} \cdot$ Samuel M. Brown ${ }^{1,2,3,5}$
}

Published online: 18 October 2017

(C) Springer Science+Business Media, LLC 2017

\begin{abstract}
Purpose of Review This review provides an overview of the evidence for and current practices incorporating the use of echocardiography in the intensive care setting. We describe training and certification for critical care echocardiography and the use of echocardiography for the assessment of hemodynamics, fluid responsiveness, diagnosis of shock, procedural guidance, and cardiac arrest.

Recent Findings Recent advances have been made in multiple aspects of critical care echocardiography, including training and certification, assessment of fluid responsiveness in spontaneously breathing patients, and evaluation of undifferentiated shock.

Summary Echocardiography is increasingly used in the intensive care setting. Its applications and evidence base continue to expand. Randomized controlled trials are needed to demonstrate that the use of echocardiography improves patient outcomes.
\end{abstract}

This article is part of the Topical Collection on Echocardiography

Samuel M. Brown

Samuel.brown@imail.org

1 Division of Pulmonary and Critical Care Medicine, University of Utah School of Medicine, Salt Lake City, UT 84132, USA

2 Division of Pulmonary and Critical Care Medicine, Intermountain Medical Center, Murray, UT 84107, USA

3 Critical Care Echocardiography Service, Intermountain Medical Center, Murray, UT 84107, USA

4 Division of Critical Care, Department of Pediatrics, University of Utah School of Medicine, Salt Lake City, UT 84108, USA

5 Shock Trauma ICU, 5121 South Cottonwood Street, Murray, UT 84107, USA
Keywords Echocardiography $\cdot$ Critical care .

Hemodynamics $\cdot$ Fluid therapy $\cdot$ Shock $\cdot$ Heart arrest

\section{Introduction}

Echocardiography is ubiquitous in the entire range of contemporary intensive care units (ICUs). Use of echocardiography has grown exponentially over the past two decades. Current guidelines recommend the use of echocardiography in a wide spectrum of clinical settings in the ICU [1-4]. This review addresses the application of echocardiography in adult ICUs. The use of echocardiography in advanced cardiac support, including extra-corporeal life support and ventricular assist devices, is outside the scope of this review. This review will cover training and certification in critical care ultrasound and the use of echocardiography for the assessment of hemodynamics, fluid responsiveness, diagnosis and management of shock, procedural guidance, and cardiac arrest.

Echocardiography is a versatile and accessible tool in the intensivist's imaging toolbox. Echocardiography can be performed at the bedside, does not use ionizing radiation, and avoids the logistical challenges associated with managing a critically ill patient with multiple life-support devices in a radiology suite [5].

Focused critical care echocardiography (FCCE), performed and interpreted, often serially in rapid succession, by a clinician at the bedside, is becoming commonplace as more clinicians are trained in FCCE [6]. Competency in basic FCCE may even be approaching a new standard of care for contemporary intensive care clinicians. Smaller ultrasound equipment with increasingly high-quality images makes routine use more feasible than in prior decades. FCCE is generally complemented by a formal, traditional echocardiogram, performed by a trained sonographer, and interpreted separately by 
a board certified echocardiographer. FCCE is normally integrated with lung/pleural, vascular, and abdominal ultrasonography in the assessment and management of critically ill patients. Rather than perform a complete assessment of cardiac function, FCCE is used to rapidly answer specific clinical questions, such as whether a patient is fluid responsive or has a pericardial effusion. These practical, straightforward questions of immediate relevance to patient management can be quickly answered at the bedside without a complete echocardiogram. Transesophageal echocardiography (TEE) is used with some frequency in the ICU, both for complete and FCCE examinations. The higher level of training required to perform TEE, the additional need for equipment cleaning and monitoring, and the invasive nature of the procedure, make it a more cumbersome tool than transthoracic echocardiography (TTE). However, TEE has excellent image quality and an indwelling TEE probe can be left in place for $72 \mathrm{~h}$ for ongoing hemodynamic monitoring (turning the probe off between serial examinations but not removing it from the esophagus) $[7 \cdot]$.

Part of the allure of FCCE is the lack of procedural risk (beyond the minor risk of TEE, echocardiography is essentially risk free as a procedure). However, misdiagnosis is a risk, especially when a less skilled clinician applies FCCE. The quality of image acquisition and interpretation are dependent on operator skill, and clinicians, especially novices, may not know what they do not know. For example, if a novice echocardiographer notes an epicardial fat pad and believes it to be a pericardial effusion, they may perform pericardiocentesis in a patient with severe hemodynamic instability unrelated to tamponade. The results could be disastrous even though the TTE procedure itself bore no intrinsic physical risks. Clinicians must therefore be aware of their technical and conceptual limitations and only apply echocardiography within the scope of their ability. A commitment to quality assurance and continuous education is crucial.

\section{Training and Certification}

FCCE is a relatively new component of the practice of critical care medicine. As such, recommendations regarding training and competency standards have been published only within the past decade. Expert consensus guidelines do now describe competency standards in critical care ultrasound. Basic FCCE is an essential component of critical care ultrasound, along with pleural/lung, abdominal, and vascular imaging. In these guidelines, competency standards for FCCE are divided into basic and advanced categories. Basic FCCE is comprised of a 2D and color Doppler assessment. The basic FCCE practitioner must be able to qualitatively describe left and right ventricular function as well as identify major abnormalities that may be life threatening, such as severe hypovolemia, pericardial tamponade, and severe valvular dysfunction. Advanced competency in FCCE includes quantitative assessments of cardiac function as well as a complete Doppler exam, similar to traditional echocardiograms performed and interpreted by cardiologists [8]. A parallel set of expert guidelines delineates the required training to achieve the competency standards described above. These guidelines recommend that $10 \mathrm{~h}$ of training and the performance of 30 supervised TTEs could support competency in basic critical care echocardiography. For advanced critical care echocardiography, $40 \mathrm{~h}$ of didactic and practical training and 150 proctored exams are recommended as the minimum standard for competency [9].

Formal certification programs for critical care echocardiography remain a work in progress. At present, some specialty societies offer a "certification of completion" for training programs in critical care echocardiography [10]. French critical care physicians have been leaders in the field of critical care echocardiography and France currently has a board certification program in critical care echocardiography [11]. Anecdotally, many advanced critical care echocardiographers in North America have obtained testamur status on the Examination of Special Competence in Adult Echocardiography (ASCeXAM) of the National Board of Echocardiography (NBE). The NBE anticipates a new board examination in advanced critical care echocardiography by early 2019 [12••].

\section{Hemodynamic Evaluation Using Echocardiography}

Perturbations in the cardiovascular and respiratory systems are a cardinal feature of critical illness. Defining these perturbations and their response to interventions allows for thoughtful and targeted management of shock and respiratory failure. Right heart catheterization (RHC), standard of care for decades, allows for direct pressure measurements in the heart and central vessels. However, it is an invasive procedure and multiple randomized controlled trials in different clinical settings have not shown benefit [13-18]. Nevertheless, echocardiography can be used to estimate pressures in the heart (Table 1). Unlike a RHC, FCCE does not have associated procedural risks and provides functional and diagnostic information in addition to pressure estimates. These attributes raise the possibility that FCCE may be beneficial in hemodynamic evaluation and management of ICU patients, although such benefits remain to be demonstrated in randomized controlled trials.

The challenge for researchers and clinicians will be ascertaining how to best employ hemodynamic information obtained from FCCE to actually improve patient outcomes. At the present time, there is insufficient data that demonstrates a meaningful benefit from echocardiography-guided management of the critically ill patient. Prospective controlled trials are essential to ensure that the rapid growth in the use of 
Table 1 Right heart catheter measurements and comparable echocardiographic parameters

\begin{tabular}{ll}
\hline Right heart catheter measure & Echocardiographic parameter \\
\hline $\begin{array}{l}\text { Central venous pressure } \\
\text { Right ventricular systolic pressure }\end{array}$ & $\begin{array}{r}\text { IVC diameter and collapsibility } \\
\text { Peak tricuspid regurgitant velocity converted to a pressure gradient } \\
\text { using the simplified Bernoulli equation plus estimated }\end{array}$ \\
$\begin{array}{l}\text { CVP—or-pulmonary acceleration time } \\
\begin{array}{l}\text { Left atrial pressure (pulmonary artery } \\
\text { occlusion pressure) }\end{array}\end{array}$ & $\begin{array}{l}\text { Left or right ventricular outflow tract velocity time integral multiplied } \\
\text { btroke volume/cardiac output } \\
\text { by heart rate to obtain the cardiac output }\end{array}$ \\
\end{tabular}

critical care echocardiography translates into improved patient outcomes. We acknowledge the relative lack of such controlled trials in general echocardiography as well; critical care echocardiography is not uniquely limited in its evidence base.

\section{Central Venous Pressure}

Central venous pressure (CVP) may be measured by RHC or central venous catheter. CVP, equivalent to right atrial pressure, has been used in the ICU extensively, albeit somewhat less recently on the basis of evidence suggesting that CVP does not predict fluid responsiveness [19]. Current guidelines estimate CVP using inferior vena cava (IVC) diameter, measured just proximal to the cavoatrial junction at end-expiration, in conjunction with collapsibility when the patient sniffs. Based on these parameters, CVP is estimated to be in one of 3 ranges, $0-5,10-20$, or indeterminate (often estimated at $8 \mathrm{mmHg}$ ) [20].

\section{Pulmonary Artery Pressure}

Non-invasive measurements of pulmonary artery pressure are commonly used to screen for the presence of pulmonary hypertension. The right ventricular systolic pressure (RVSP) is estimated from the tricuspid regurgitant (TR) jet peak velocity using a simplified Bernoulli equation. Unless there is significant pulmonic stenosis, the RVSP is identical to the pulmonary artery systolic pressure. Several studies have shown good correlation with this method and direct pressure transduction measurements [21-23], although some suggest limitations of this technique, especially due to variations in the CVP estimate [24]. Importantly, this method cannot be performed in the absence of tricuspid regurgitation. Mean and systolic pulmonary artery pressure may also be estimated using pulmonary acceleration time. The benefit of this method is that it does not require a tricuspid regurgitant jet $[20,25,26]$.

\section{Left Atrial Pressure}

The left atrial pressure (LAP), historically measured by the pulmonary artery occlusion pressure, is usually equivalent to the left ventricular end-diastolic pressure (LVEDP). An elevated LAP may indicate the risk of hydrostatic pulmonary edema [27-29]. LVEDP can be estimated echocardiographically using the ratio of E/e' (Fig. 1). Conceptually, the E/e' ratio combines the velocity of early left ventricular diastolic filling (highly load dependent) and the rate of early myocardial relaxation (relatively load independent). This method is generalizable to patients with an $\mathrm{EF}<50 \%$ who are in sinus rhythm or patients who meet criteria for diastolic dysfunction [30-32]. Unfortunately, studies have not demonstrated the capacity of this ratio to predict fluid responsiveness in patients, although there is some suggestion that particular patterns of E/e' may be associated with mortality [33].


Fig. 1 The ratio of the peak velocity of the pulse wave Doppler mitral inflow E-wave (a) and the peak velocity of the mitral annulus tissue doppler e' wave (b) determines the E/e' ratio. E velocity is obtained by pulse wave Doppler of the mitral valve inflow at the mitral valve leaflets during maximum excursion (c) and e' velocity is obtained by tissue Doppler of the medial (shown in d) or lateral mitral annulus 


\section{Cardiac Output}

The assessment of cardiac output is important among ICU patients. There are multiple ways of measuring cardiac output, including indicator dilution methods (whether via RHC or other technology), the Fick equation, bio-impedance/bio-reactance devices, and echocardiography (Simpson's biplane method of disks or ventricular outflow tract velocity time interval). Indicator dilution methods and the Fick method require invasive devices. Bio-reactance/bio-impedance devices or pulse contour analysis methods may require costly, specialized equipment. Echocardiography, on the other hand, is widely available and non-invasive. Echocardiographic and RHC measurements of cardiac output appear to have good correlation, although precision has not been high in most trials [34-39].

\section{Fluid Responsiveness}

The assessment of fluid responsiveness is a significant challenge in the management of circulatory failure. Fluid responsiveness is defined as an increase ( $\geq 10-15 \%)$ in stroke volume after intravascular volume expansion. Excessive fluid resuscitation is associated with respiratory and renal failure and other adverse outcomes [40-43]. The two goals of assessing fluid responsiveness are [1] to identify which patients will increase their stroke volume in response to volume expansion and [2] to avoid administration of fluid to patients who will not increase their stroke volume. The ideal metric to measure fluid responsiveness would be a quick, cheap, and easily repeatable test, validated across a broad spectrum of clinical contexts that requires minimal operator skill.

Various techniques are currently employed to predict fluid responsiveness. Historical static measures, such as CVP or pulmonary artery occlusion pressure, do not predict fluid responsiveness [19, 44, 45]. Dynamic measures, which assess the physiologic response to a rapid change in preload, predict fluid responsiveness more reliably. This change in cardiac preload may be induced by respiratory variation in intrathoracic pressure, a passive leg-raise maneuver [46•], the rapid administration of a fluid bolus $[47,48]$, or an expiratory occlusion test [49]. The passive leg-raise maneuver is performed by moving a semi-recumbent patient to a supine position with the legs raised to $45^{\circ}$. This mimics a fluid bolus by increasing the return of lower extremity and abdominal venous blood to the heart. The expiratory occlusion test is performed by pausing mechanical ventilation at end-expiration, which results in a transient increase in preload. FCCE can be used to evaluate the physiological response to these preload challenges by assessing variation in vena cava diameter (SVC or IVC) or measuring changes in stroke volume. Some dynamic measures are limited to patients who are passively mechanically ventilated, i.e., not making respiratory efforts. Some are limited to patients in sinus rhythm. Others, primarily the passive leg raise, rapid administration of fluid and the expiratory occlusion test, can be performed in the majority of patients [50].

Respiratory variation in inferior vena cava diameter is easily and quickly measured in most patients (Fig. 2). Two studies have demonstrated that respiratory changes in IVC diameter (with thresholds of 18 and $12 \%$, respectively) predicts fluid responsiveness in mechanically ventilated patients [51, 52]. Superior vena cava distensibility of $36 \%$ has also been validated as a predictor of fluid responsiveness [53]. On the basis of current evidence, these measures of caval collapsibility or distensibility require that patients be passively mechanically ventilated.

The assessment of fluid responsiveness in spontaneously breathing patients has proven a greater challenge. Passive, positive pressure mechanical ventilation administers a relatively fixed change in intrathoracic pressure during the respiratory cycle. Spontaneously breathing patients - whether mechanically ventilated or not - may have insufficient, excessive or variable respiratory effort and therefore may not predictably change cardiac preload during the respiratory cycle. However, Corl et al. recently showed that an IVC diameter variability of $25 \%$ predicts fluid responsiveness in spontaneously breathing patients with a sensitivity of $87 \%$ and a specificity of $81 \%$ [54••, 55].

Echocardiography can be used to measure the stroke volume before and after a passive leg-raise maneuver or fluid bolus to determine fluid responsiveness [46, 56]. The limitations of this technique are sonographic skill and the longer time required to obtain measurements, as compared to vena cava analysis. The advantage is the lack of reliance on passive mechanical ventilation.

Fluid responsiveness, as defined by an increase in stroke volume, is admittedly an intermediate outcome. Multiple randomized controlled trials comparing perioperative fluid management with stroke volume optimization to non-stroke volume guided management demonstrate decreased hospital length of stay and morbidity [57-64]. These results may or may not generalize to the overall ICU population. One beforeafter trial showed improved mortality and decreased renal insufficiency using an echocardiography-guided fluid and inotrope protocol in ICU patients [65••]. While this preliminary data is intriguing, it is subject to the limitations of historical controls. Prospective, randomized controlled trials are needed to determine whether echocardiographic-guided fluid management improves patient outcomes.

\section{Diagnosis and Management of Shock}

Shock is a state of tissue hypoperfusion that results in vital organ damage [66]. An accurate diagnosis of the cause of 
Fig. 2 A subcostal view of the IVC at end-expiration (left) and during inspiration (right) in a spontaneously breathing patient. This patient's IVC collapsed $35 \%$, which in the context of circulatory failure would predict fluid responsiveness
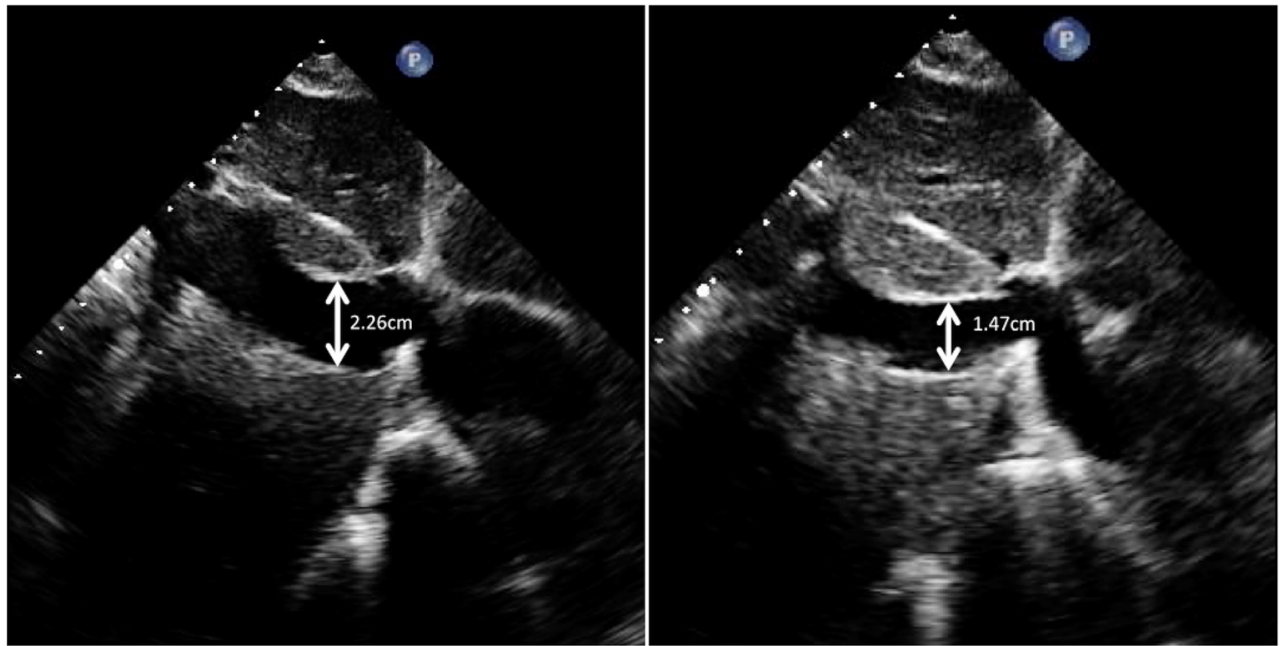

shock is essential for appropriate management. Differentiating among the types and causes of shock can be challenging in a rapidly decompensating patient. Undifferentiated or multifactorial shock is a common clinical scenario in the ICU. Echocardiography can help determine the presence or absence of LV failure, cor pulmonale, pericardial tamponade, severe hypovolemia, and other causes of shock.

\section{Undifferentiated Shock}

Multiple ultrasound protocols have been developed for the evaluation of undifferentiated shock. Most of these protocols combine FCCE with other body ultrasound, including lung/pleura, vascular, and abdominal imaging [67-70]. Multiple studies have suggested that the use of echocardiography in the setting of undifferentiated shock changes management $[6,71,72 \cdot, 73,74,75]$. However, a change in management does not necessarily result in a benefit to the patient. Studies are needed to examine the impact of FCCE protocols on patient outcomes.

Common causes of shock, their typical echocardiographic findings and current clinical use of echocardiography are presented below. In addition to the syndromes described here, other abnormalities that may cause shock can be identified using echocardiography. These include, but are not limited to, acute valvular dysfunction, intracardiac masses, and hypertrophic obstructive cardiomyopathy or related causes of dynamic outflow tract obstruction.

\section{Left Ventricular Failure}

Severe LV failure may occur in a multitude of clinical contexts. Ischemic heart disease, non-ischemic cardiomyopathies, global hypoxemia, and toxic/metabolic derangements may all cause LV failure that results in shock. Calculation of the ejection fraction (EF) by Simpson's biplane method of disks is currently the most common echocardiographic metric for the assessment of global LV function [76]. This method can be time-consuming and technically challenging depending on image quality. Visual estimation of LVEF, which can be obtained rapidly at the bedside, has been shown to closely correlate with the calculated EF, both by expert readers [77, 78] and non-expert readers [79-81]. Visual estimation is likely a more practical approach to the estimation of EF in a decompensating patient, when qualitative rather than quantitative estimates may be more relevant.

\section{Acute Cor Pulmonale}

Acute cor pulmonale (ACP) is common in the ICU. Pulmonary embolism (PE) and acute respiratory distress syndrome (ARDS) are two of the more common etiologies of ACP managed by intensivists [82]. Echocardiographic parameters that are used to establish the presence of cor pulmonale include RV to LV end-diastolic area ratio $>1.0$, [83], eccentricity index $>1$ (D-shape of the interventricular septum) [84], $\mathrm{RV}$ fractional area change $<35 \%$, tricuspid annular plane systolic excursion $<16 \mathrm{~mm}$, and RVSP $>35 \mathrm{mmHg}$ measured from the tricuspid regurgitant jet [20]. Right ventricular hypertrophy and trabeculation may help differentiate between acute and chronic cor pulmonale [85].

Echocardiography plays a complex role in the diagnosis of PE. Contrasted computed tomographic imaging and ventilation-perfusion scans are the indicated tests for the diagnosis of PE. However, patient instability, renal insufficiency or pulmonary parenchymal disease may prohibit these modalities. In these situations, echocardiography can be used as supporting evidence for the presence or absence of PE, but rarely can make the diagnosis on its own. Thrombus in transit may occasionally be seen directly on TTE, however the sensitivity of TTE for the diagnosis of PE is poor [86-88]. Two particular patterns of RV dysfunction, the "McConnell sign" 
[89] and "60-60 sign" [90] have been described as specific to $\mathrm{PE}$ as compared to other causes of acute RV dysfunction. The McConnell sign refers to right ventricular free wall hypokinesis with apical sparing. The 60-60 sign refers to a right ventricular acceleration time $\leq 60 \mathrm{~ms}$ in conjunction with a tricuspid regurgitant pressure gradient of $\leq 60 \mathrm{mmHg}$. Despite initial promise, the McConnell sign was subsequently found to only have $33 \%$ specificity for PE when compared to $\mathrm{RV}$ infarction. Its primary utility at present is in distinguishing acute from chronic cor pulmonale rather than indicating the reason for the cor pulmonale [91]. A subsequent evaluation of the 60-60 sign found a specificity of only $69 \%$, much lower than the original $94 \%$ reported [92]. Future studies may incorporate combinations of these signs and other indices of RV failure to develop more specific echocardiographic parameters for the diagnosis of acute PE. At present, TTE is neither sensitive nor specific for the diagnosis of acute PE. TEE has better sensitivity (Fig. 3), ranging from 77 to $97 \%$ for central PE ("saddle embolus"), but is not sufficient for detecting acute $\mathrm{PE}$ in general [88, 93-95]. Nazerian et al. found a sensitivity for PE of $90 \%$ when echocardiography was combined with vascular and lung ultrasound in patients with a Well's score $>4$ and a positive d-dimer [96]. These results merit external validation to support this as a possible method for the diagnosis or exclusion of PE. While echocardiography can only rarely make the diagnosis of acute PE, the absence of ACP on an echocardiogram suggests that massive PE is unlikely to be the cause of shock.

In terms of risk stratification, echocardiographic findings of ACP portend a worse prognosis in the setting of acute PE [97-100]. Thrombolysis decreases mortality in massive PE, which is defined as PE causing systemic hypotension [101]. PE that causes right heart dysfunction without causing systemic hypotension is commonly referred to as a submassive PE. The
PEITHOS trial, which is the largest and most robust trial examining thrombolysis for submassive PE, found that thrombolysis did not impact patient mortality [102]. A meta-analysis of 16 trials that studied thrombolysis for PE suggested a possible mortality benefit associated with thrombolysis in submassive PE [103]. Echocardiography may be used as a prognostic indicator in the setting of acute PE, but at present, there is insufficient evidence that echocardiographic findings can be used to guide management and impact patient outcomes.

ACP is a complication in 20-25\% of cases of ARDS, with higher incidence when more severe [104]. When severe, ACP may be associated with increased mortality [105-107]. Risk factors for the presence of ACP complicating ARDS include pneumonia as the cause of ARDS, driving pressure $\geq 18 \mathrm{cmH} 2 \mathrm{O}, \mathrm{PaO}_{2} / \mathrm{FiO}_{2}$ ratio $<150$ and $\mathrm{PaCO}_{2} \geq 48 \mathrm{mmHg}$ [106]. TEE-guided "right ventricular protective" management of ARDS has been proposed as a method to decrease mortality in severe ARDS. This strategy entails targeted ventilator management and consideration of prone position to decrease the plateau pressure, improve oxygenation, and decrease $\mathrm{PaCO}_{2}$ [108]. Clinical trials are needed to study the efficacy of RV protective ventilation. Currently, echocardiography can be used to help differentiate acute cor pulmonale from other causes of shock in patients with ARDS.

\section{Pericardial Tamponade}

Pericardial tamponade is an important, albeit less common, diagnostic consideration in patients with undifferentiated shock. Definitive management requires pericardiocentesis or equivalent drainage. The prevalence of pericardial tamponade in undifferentiated shock is not well described. A history of trauma or a cardiac intervention often provides a clue that tamponade may be present. However, tamponade can be a
Fig. 3 A transesophageal echocardiogram view of a clot-intransit




complication of infectious, inflammatory, uremic, or neoplastic diseases and therefore may present more subtly. These subtle presentations are when echocardiography becomes an indispensible tool for diagnosis [109]. Characteristic echocardiographic findings of tamponade include the presence of a pericardial effusion, plethoric IVC, right ventricular diastolic collapse, right atrial systolic collapse, septal bounce (neither sensitive nor specific), $>60 \%$ inspiratory decrease in tricuspid peak E-wave velocity, and a $>30 \%$ inspiratory decrease in mitral peak E-wave velocity [110]. The pulse wave Doppler interpretation for inflow velocity variability is part of advanced FCCE, but establishing the presence of a pericardial effusion, looking for right sided collapse and IVC plethora using 2D ultrasound are essential skills for even basic FCCE.

\section{Hypovolemic Shock}

Hypovolemic shock occurs in the setting of hemorrhage or excessive intestinal, urinary, or insensible fluid losses. Echocardiographic findings in severe hypovolemia may include a small and collapsible IVC, supranormal LVEF, complete collapse of the LV during systole ("kissing walls"), small LV end-diastolic area, and dynamic intraventricular outflow obstruction [111]. Hypovolemia may complicate other types of shock, so not all of these findings will necessarily be present in the hypovolemic patient.

\section{Septic Shock}

A broad spectrum of cardiac dysfunction is associated with septic shock. Worse LV strain, LV systolic and diastolic dysfunction, and RV systolic and diastolic dysfunction have all been described in patients with sepsis $[112 \cdot, 113,114,115]$. Septic shock can be complicated by cardiogenic shock when the cardiac dysfunction induced by the septic milieu is severe. Given the array of hemodynamic profiles seen in the septic patient, echocardiography may be used in the context of septic shock to help delineate the particular hemodynamics of an individual patient. Echocardiography-guided fluid and vasoactive medication protocols are being studied presently [116], but as of yet there is only preliminary data that they may be efficacious [65].

\section{Procedural Guidance}

Ultrasound guidance is used for most bedside procedures in the ICU in the contemporary environment. It is considered standard of care for central venous catheter insertion [117-119] and is used commonly for arterial catheter placement, thoracentesis, paracentesis, and even confirmation of tube placement after endotracheal intubation [120]. Echocardiography specifically can be used to guide the placement of central venous catheters (CVC) and pulmonary artery catheters [121]. Visualization of the guidewire in the right atrium confirms correct guidewire placement prior to dilation of the vessel (Fig. 4). Injection of saline through an internal jugular, subclavian, or femoral CVC with subsequent echocardiographic visualization of bubbles in the right atrium within $2 \mathrm{~s}$ is likely another sensitive method to confirm appropriate catheter placement $[122,123]$. Very large sample sizes are needed for studies of catheter misplacement because of the low rate of occurrence, so the precise sensitivity of this method is unknown and will likely remain so. Raman et al. describe a technique using real-time echocardiography during CVC
Fig. 4 A bright guidewire is identified in the right atrium during central venous catheter placement. Visualization of the guidewire in the right atrium ensures correct placement prior to dilation of the vessel

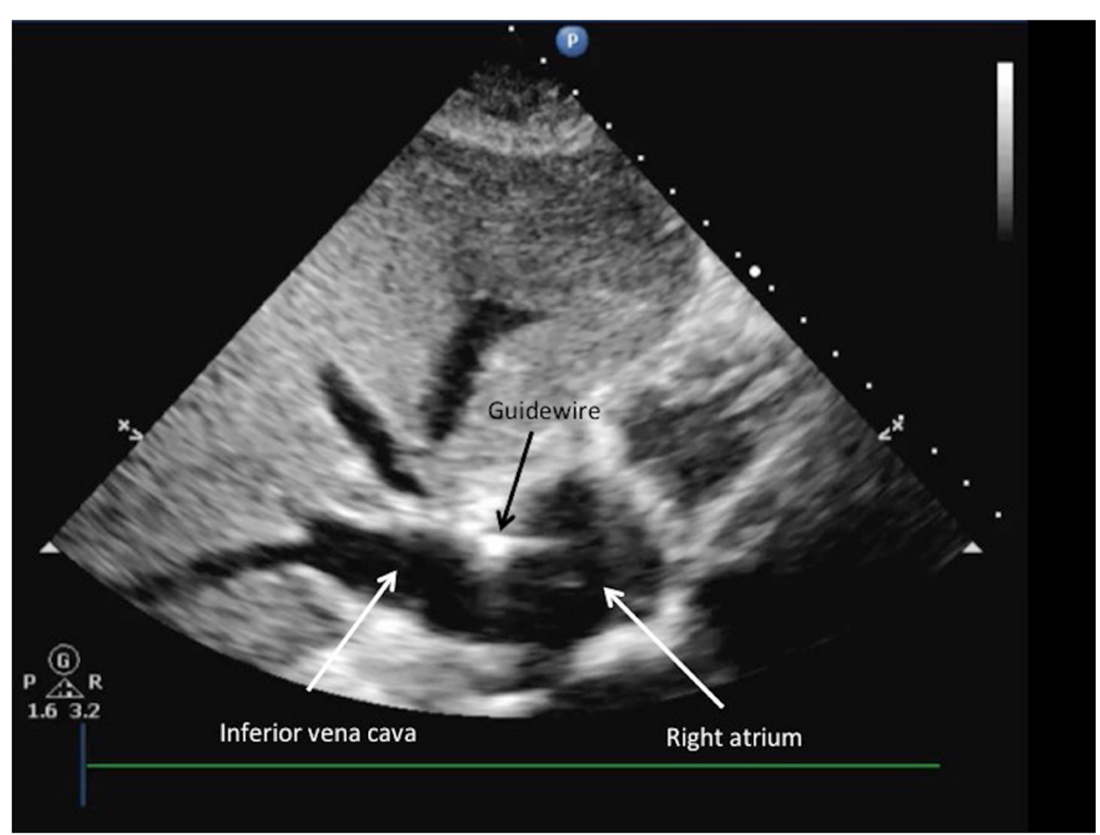


placement to confirm precise catheter placement at the junction of the right atrium and superior vena cava. When combined with lung ultrasound to rule out pneumothorax, this technique may obviate the need for post-insertion chest $\mathrm{x}$ ray and decrease the time between insertion and catheter use [124•]. One challenge of real-time echocardiography during catheter placement is the need for two skilled operators during the procedure. One operator is sterile and placing the catheter, while the other operator is non-sterile and must be able to obtain an adequate echocardiographic view.

\section{Cardiac Arrest}

Echocardiography has emerged over the past decade as a diagnostic and prognostic tool for use during advanced cardiac life support (ACLS). Current guidelines make a IIb recommendation that echocardiography can be considered for use during ACLS [125]. The primary treatment of pulseless electrical activity (PEA) and asystole is the correction of reversible causes of cardiac arrest. It may be difficult to diagnose hypovolemia, pericardial tamponade, severe RV failure, and severe LV failure at the bedside without additional diagnostic testing. Echocardiography can aid in the diagnosis of all of the above causes of cardiac arrest.

Several prospective trials, in various clinical contexts, have shown that echocardiography can successfully be used during ACLS to identify reversible causes of cardiac arrest [126-128]. One small trial, using historical controls, found a survival benefit when echocardiography was used in conjunction with end-tidal capnography to change the ACLS protocol and administer vasopressin [129]. Additional trials are needed to solidify the ability of echocardiography to assist with diagnosis and management during ACLS.

The presence of mechanical cardiac activity seen with FCCE can help predict outcomes following ACLS [130•]. A recent meta-analysis suggested that the absence of cardiac activity seen with ultrasound has a negative likelihood ratio of 0.06 (95\% CI 0.01-0.39) for predicting ROSC [131]. This suggests that the absence of cardiac activity on ultrasound is a strong predictor of death after ACLS efforts. This may be used as one data point in the decision to terminate resuscitation efforts.

Multiple protocols have been proposed for echocardiography during ACLS [132-134]. In our experience, the "focused echocardiographic evaluation during life support" (FEEL) protocol is the favored approach [132]. The FEEL protocol is a structured approach to obtaining a subcostal view during a pulse check without prolonging breaks between compressions. The imperative in the use of echocardiography during ACLS is to not interrupt chest compressions, which are known to be strongly associated with improved outcome [135].

\section{Conclusions}

Echocardiography has exploded into the world of the ICU over the last two decades. It is a promising tool to help practitioners who care for the critically ill understand the diagnoses and hemodynamics affecting the individual patient. Prospective trials comparing echocardiography-guided management versus non-echocardiography-guided management in specific clinical situations will enhance how practitioners use echocardiography to positively impact patient outcomes.

\section{Compliance with Ethical Standards}

Conflict of Interest All authors declare that they have no conflict of interest.

Human and Animal Rights and Informed Consent All reported studies/experiments with human or animal subjects performed by the authors have been previously published and complied with all applicable ethical standards (including the Helsinki declaration and its amendments, institutional/national research committee standards, and international/national/institutional guidelines).

\section{References}

Papers of particular interest, published recently, have been highlighted as:

- Of importance

•• Of major importance

1. Levitov A, Frankel HL, Blaivas M, Kirkpatrick AW, Su E, Evans $\mathrm{D}$, et al. Guidelines for the appropriate use of bedside general and cardiac ultrasonography in the evaluation of critically Ill patients-Part II: cardiac ultrasonography. Crit Care Med. 2016;44(6):1206-27.

2. Papolos A, Narula J, Bavishi C, Chaudhry FA, Sengupta PP. U.S. hospital use of echocardiography: insights from the nationwide inpatient sample. J Am Coll Cardiol. 2016;67(5):502-11.

3. Via G, Hussain A, Wells M, Reardon R, ElBarbary M, Noble VE, et al. International evidence-based recommendations for focused cardiac ultrasound. J Am Soc Echocardiogr : Off Publ Am Soc Echocardiogr. 2014;27(7):683 e1-e33.

4. Porter TR, Shillcutt SK, Adams MS, Desjardins G, Glas KE, Olson JJ, et al. Guidelines for the use of echocardiography as a monitor for therapeutic intervention in adults: a report from the American Society of Echocardiography. J Am Soc Echocardiogr : Off Publ Am Soc Echocardiogr. 2015;28(1):40-56.

5. Schwebel C, Clec'h C, Magne S, Minet C, Garrouste-Orgeas M, Bonadona A, et al. Safety of intrahospital transport in ventilated critically ill patients: a multicenter cohort study*. Crit Care Med. 2013;41(8):1919-28.

6. Zieleskiewicz L, Muller L, Lakhal K, Meresse Z, Arbelot C, Bertrand PM, et al. Point-of-care ultrasound in intensive care units: assessment of 1073 procedures in a multicentric, prospective, observational study. Intensive Care Med. 2015;41(9):1638-47.

7. Vieillard-Baron A, Slama M, Mayo P, Charron C, Amiel JB, Esterez C, et al. A pilot study on safety and clinical utility of a single-use 72-hour indwelling transesophageal echocardiography probe. Intensive Care Med. 2013;39(4):629-35. TEE provides 
excellent image quality once the probe is inserted. VieillardBaron et al show that an indwelling probe is both feasible and safe.

8. Mayo PH, Beaulieu Y, Doelken P, Feller-Kopman D, Harrod C, Kaplan A, et al. American College of Chest Physicians/La Societe de Reanimation de Langue Francaise statement on competence in critical care ultrasonography. Chest. 2009;135(4):1050-60.

9. International expert statement on training standards for critical care ultrasonography. Intensive Care Med. 2011;37(7):1077-83.

10. [07/21/2017]. Available from: http://www.chestnet.org/Education/ Advanced-Clinical-Training/Certificate-of-Completion-Program/ Critical-Care-Ultrasonography.

11. Vieillard-Baron A, Slama M, Cholley B, Janvier G, Vignon P. Echocardiography in the intensive care unit: from evolution to revolution? Intensive Care Med. 2008;34(2):243-9.

12.• Mayo PH, Narasimhan M, Koenig S. Advanced critical care echocardiography: the intensivist as the ACCE of hearts. Chest. 2017;152(1):4-5. A board examination for critical care ultrasonograpay is expected for early 2019, an important step in critical care echocardiography.

13. Binanay C, Califf RM, Hasselblad V, O'Connor CM, Shah MR, Sopko G, et al. Evaluation study of congestive heart failure and pulmonary artery catheterization effectiveness: the ESCAPE trial. JAMA. 2005;294(13):1625-33.

14. Harvey S, Harrison DA, Singer M, Ashcroft J, Jones CM, Elbourne D, et al. Assessment of the clinical effectiveness of pulmonary artery catheters in management of patients in intensive care (PAC-Man): a randomised controlled trial. Lancet (London, England). 2005;366(9484):472-7.

15. Rhodes A, Cusack RJ, Newman PJ, Grounds RM, Bennett ED. A randomised, controlled trial of the pulmonary artery catheter in critically ill patients. Intensive Care Med. 2002;28(3):256-64.

16. Richard C, Warszawski J, Anguel N, Deye N, Combes A, Barnoud $\mathrm{D}$, et al. Early use of the pulmonary artery catheter and outcomes in patients with shock and acute respiratory distress syndrome: a randomized controlled trial. JAMA. 2003;290(20):2713-20.

17. Sandham JD, Hull RD, Brant RF, Knox L, Pineo GF, Doig CJ, et al. A randomized, controlled trial of the use of pulmonary-artery catheters in high-risk surgical patients. N Engl J Med. 2003;348(1):5-14.

18. Wheeler AP, Bernard GR, Thompson BT, Schoenfeld D, Wiedemann HP, deBoisblanc B, et al. Pulmonary-artery versus central venous catheter to guide treatment of acute lung injury. N Engl J Med. 2006;354(21):2213-24.

19. Marik PE, Baram M, Vahid B. Does central venous pressure predict fluid responsiveness? A systematic review of the literature and the tale of seven mares. Chest. 2008;134(1):172-8.

20. Rudski LG, Lai WW, Afilalo J, Hua L, Handschumacher MD, Chandrasekaran K, et al. Guidelines for the echocardiographic assessment of the right heart in adults: a report from the American Society of Echocardiography endorsed by the European Association of Echocardiography, a registered branch of the European Society of Cardiology, and the Canadian Society of Echocardiography. J Am Soc Echocardiogr: Off Publ Am Soc Echocardiogr. 2010;23(7):685-713. quiz 86-8

21. Yock PG, Popp RL. Noninvasive estimation of right ventricular systolic pressure by Doppler ultrasound in patients with tricuspid regurgitation. Circulation. 1984;70(4):657-62.

22. Currie PJ, Seward JB, Chan KL, Fyfe DA, Hagler DJ, Mair DD, et al. Continuous wave Doppler determination of right ventricular pressure: a simultaneous Doppler-catheterization study in $127 \mathrm{pa}-$ tients. J Am Coll Cardiol. 1985;6(4):750-6.

23. D'Alto M, Romeo E, Argiento P, D'Andrea A, Vanderpool R, Correra A, et al. Accuracy and precision of echocardiography versus right heart catheterization for the assessment of pulmonary hypertension. Int J Cardiol. 2013;168(4):4058-62.
24. Fisher MR, Forfia PR, Chamera E, Housten-Harris T, Champion $\mathrm{HC}$, Girgis RE, et al. Accuracy of Doppler echocardiography in the hemodynamic assessment of pulmonary hypertension. Am J Respir Crit Care Med. 2009;179(7):615-21.

25. Yared K, Noseworthy P, Weyman AE, McCabe E, Picard MH, Baggish AL. Pulmonary artery acceleration time provides an accurate estimate of systolic pulmonary arterial pressure during transthoracic echocardiography. J Am Soc Echocardiogr: Off Publ Am Soc Echocardiogr. 2011;24(6):687-92.

26. Kitabatake A, Inoue M, Asao M, Masuyama T, Tanouchi J, Morita $\mathrm{T}$, et al. Noninvasive evaluation of pulmonary hypertension by a pulsed Doppler technique. Circulation. 1983;68(2):302-9.

27. Hall JE. Guyton and Hall textbook of medical physiology: Elsevier Health Sci; 2015.

28. Gehlbach BK, Geppert E. The pulmonary manifestations of left heart failure. Chest. 2004;125(2):669-82.

29. Gaar KA Jr, Taylor AE, Owens LJ, Guyton AC. Effect of capillary pressure and plasma protein on development of pulmonary edema. Am J Phys. 1967;213(1):79-82.

30. Ommen SR, Nishimura RA, Appleton CP, Miller FA, JK O, Redfield MM, et al. Clinical utility of Doppler echocardiography and tissue Doppler imaging in the estimation of left ventricular filling pressures: a comparative simultaneous Dopplercatheterization study. Circulation. 2000;102(15):1788-94.

31. Nagueh SF, Smiseth OA, Appleton CP, Byrd BF 3rd, Dokainish H, Edvardsen $\mathrm{T}$, et al. Recommendations for the evaluation of left ventricular diastolic function by echocardiography: an update from the American Society of Echocardiography and the European Association of Cardiovascular Imaging. J Am Soc Echocardiogr: Off Publ Am Soc Echocardiogr. 2016;29(4):277-314.

32. Ritzema JL, Richards AM, Crozier IG, Frampton CF, Melton IC, Doughty RN, et al. Serial Doppler echocardiography and tissue Doppler imaging in the detection of elevated directly measured left atrial pressure in ambulant subjects with chronic heart failure. JACC Cardiovasc Imaging. 2011;4(9):927-34.

33. Brown SM, Pittman JE, Hirshberg EL, Jones JP, Lanspa MJ, Kuttler KG, et al. Diastolic dysfunction and mortality in early severe sepsis and septic shock: a prospective, observational echocardiography study. Crit Ultrasound J. 2012;4(1):8.

34. Axler O, Tousignant C, Thompson CR, Dall'ava-Santucci J, Phang PT, Russell JA, et al. Comparison of transesophageal echocardiographic, fick, and thermodilution cardiac output in critically ill patients. J Crit Care. 1996;11(3):109-16.

35. Estagnasie P, Djedaini K, Mier L, Coste F, Dreyfuss D. Measurement of cardiac output by transesophageal echocardiography in mechanically ventilated patients. Comparison with thermodilution. Intensive Care Med. 1997;23(7):753-9.

36. Hammoudi N, Hekimian G, Laveau F, Achkar M, Isnard R, Combes A. Three-dimensional transoesophageal echocardiography for cardiac output in critically ill patients: A pilot study of ultrasound versus the thermodilution method. Arch Cardiovasc Dis. 2017;110(1):7-13.

37. McLean AS, Needham A, Stewart D, Parkin R. Estimation of cardiac output by noninvasive echocardiographic techniques in the critically ill subject. Anaesth Intensive Care. 1997;25(3):250-4.

38. Poelaert J, Schmidt C, Van Aken H, Hinder F, Mollhoff T, Loick HMA. comparison of transoesophageal echocardiographic Doppler across the aortic valve and the thermodilution technique for estimating cardiac output. Anaesthesia. 1999;54(2):128-36.

39. Wetterslev M, Moller-Sorensen H, Johansen RR, Perner A. Systematic review of cardiac output measurements by echocardiography vs. thermodilution: the techniques are not interchangeable. Intensive Care Med. 2016;42(8):1223-33.

40. Boyd JH, Forbes J, Nakada TA, Walley KR, Russell JA. Fluid resuscitation in septic shock: a positive fluid balance and elevated 
central venous pressure are associated with increased mortality. Crit Care Med. 2011;39(2):259-65.

41. Silva JM Jr, de Oliveira AM, Nogueira FA, Vianna PM, Pereira Filho MC, Dias LF, et al. The effect of excess fluid balance on the mortality rate of surgical patients: a multicenter prospective study. Critical Care (London, England). 2013;17(6):R288.

42. Sadaka F, Juarez M, Naydenov S, O'Brien J. Fluid resuscitation in septic shock: the effect of increasing fluid balance on mortality. J Intensive Care Med. 2014;29(4):213-7.

43. Sakr Y, Rubatto Birri PN, Kotfis K, Nanchal R, Shah B, Kluge S, et al. Higher fluid balance increases the risk of death from sepsis: results from a large international audit. Crit Care Med. 2017;45(3): 386-94.

44. Kumar A, Anel R, Bunnell E, Habet K, Zanotti S, Marshall S, et al. Pulmonary artery occlusion pressure and central venous pressure fail to predict ventricular filling volume, cardiac performance, or the response to volume infusion in normal subjects. Crit Care Med. 2004;32(3):691-9.

45. Osman D, Ridel C, Ray P, Monnet X, Anguel N, Richard C, et al. Cardiac filling pressures are not appropriate to predict hemodynamic response to volume challenge. Crit Care Med. 2007;35(1): 64-8.

46. Monnet X, Marik P, Teboul JL. Passive leg raising for predicting fluid responsiveness: a systematic review and meta-analysis. Intensive Care Med. 2016;42(12):1935-47. The passive leg raise allows clinicians to assess volume responsiveness regardless of cardiac rhythm and respiratory status and without actual administration of fluid in patients who may no tolerate fluid.

47. Muller L, Toumi M, Bousquet PJ, Riu-Poulenc B, Louart G, Candela D, et al. An increase in aortic blood flow after an infusion of $100 \mathrm{ml}$ colloid over 1 minute can predict fluid responsiveness: the mini-fluid challenge study. Anesthesiology. 2011;115(3):541-7.

48. Wu Y, Zhou S, Zhou Z, Liu BA. 10-second fluid challenge guided by transthoracic echocardiography can predict fluid responsiveness. Critical Care (London, England). 2014;18(3):R108.

49. Monnet X, Osman D, Ridel C, Lamia B, Richard C, Teboul JL. Predicting volume responsiveness by using the end-expiratory occlusion in mechanically ventilated intensive care unit patients. Crit Care Med. 2009;37(3):951-6.

50. Monnet XT, Teboul J.L. Volume expansion and fluid responsiveness. In: Brown SMB, Hirshberg, E., Kasal, J., Pustavoitau, A., editor. Comprehensive critical care ultrasound. Mount Prospect: Society of Critical Care Medicine; 2015. p. 61-69.

51. Barbier C, Loubieres Y, Schmit C, Hayon J, Ricome JL, Jardin F, et al. Respiratory changes in inferior vena cava diameter are helpful in predicting fluid responsiveness in ventilated septic patients. Intensive Care Med. 2004;30(9):1740-6.

52. Feissel M, Michard F, Faller JP, Teboul JL. The respiratory variation in inferior vena cava diameter as a guide to fluid therapy. Intensive Care Med. 2004;30(9):1834-7.

53. Vieillard-Baron A, Chergui K, Rabiller A, Peyrouset O, Page B, Beauchet A, et al. Superior vena caval collapsibility as a gauge of volume status in ventilated septic patients. Intensive Care Med. 2004;30(9):1734-9.

54.• Corl KA, George NR, Romanoff J, Levinson AT, Chheng DB, Merchant RC, et al. Inferior vena cava collapsibility detects fluid responsiveness among spontaneously breathing critically-ill patients. J Crit Care. 2017;41:130-7. Options for determining fluid responsiveness in a spontaneously breathing patient have historically been quite limited. This paper provides useful validation of an echocardiographic technique for application in spontaneously breathing patient.

55. Lanspa MJ, Grissom CK, Hirshberg EL, Jones JP, Brown SM. Applying dynamic parameters to predict hemodynamic response to volume expansion in spontaneously breathing patients with septic shock. Shock (Augusta, Ga). 2013;39(2):155-60.
56. Lafanechere A, Pene F, Goulenok C, Delahaye A, Mallet V, Choukroun $\mathrm{G}$, et al. Changes in aortic blood flow induced by passive leg raising predict fluid responsiveness in critically ill patients. Critical Care (London, England). 2006;10(5):R132.

57. Conway DH, Mayall R, Abdul-Latif MS, Gilligan S, Tackaberry C. Randomised controlled trial investigating the influence of intravenous fluid titration using oesophageal Doppler monitoring during bowel surgery. Anaesthesia. 2002;57(9):845-9.

58. Gan TJ, Soppitt A, Maroof M, El-Moalem H, Robertson KM, Moretti E, et al. Goal-directed intraoperative fluid administration reduces length of hospital stay after major surgery. Anesthesiology. 2002;97(4):820-6.

59. McKendry M, McGloin H, Saberi D, Caudwell L, Brady AR, Singer M. Randomised controlled trial assessing the impact of a nurse delivered, flow monitored protocol for optimisation of circulatory status after cardiac surgery. BMJ (Clin Res ed). 2004;329(7460):258.

60. Mythen MG, Webb AR. Perioperative plasma volume expansion reduces the incidence of gut mucosal hypoperfusion during cardiac surgery. Arch Surg (Chicago, Ill : 1960). 1995;130(4):423-9.

61. Noblett SE, Snowden CP, Shenton BK, Horgan AF. Randomized clinical trial assessing the effect of Doppler-optimized fluid management on outcome after elective colorectal resection. Br J Surg. 2006;93(9):1069-76.

62. Sinclair S, James S, Singer M. Intraoperative intravascular volume optimisation and length of hospital stay after repair of proximal femoral fracture: randomised controlled trial. BMJ (Clin Res ed). 1997;315(7113):909-912.

63. Venn R, Steele A, Richardson P, Poloniecki J, Grounds M, Newman P. Randomized controlled trial to investigate influence of the fluid challenge on duration of hospital stay and perioperative morbidity in patients with hip fractures. Br J Anaesth. 2002;88(1):65-71.

64. Wakeling HG, McFall MR, Jenkins CS, Woods WG, Miles WF, Barclay GR, et al. Intraoperative oesophageal Doppler guided fluid management shortens postoperative hospital stay after major bowel surgery. Br J Anaesth. 2005;95(5):634-42.

65.• Kanji HD, McCallum J, Sirounis D, MacRedmond R, Moss R, Boyd JH. Limited echocardiography-guided therapy in subacute shock is associated with change in management and improved outcomes. J Crit Care. 2014;29(5):700-5. Kanji et al's work is the only prospective data, to our knowledge and admitting the limitations of before-after design, that associates the use of FCCE with improved clinical outcomes in general ICU patients.

66. Hall J, Schmidt G, Kress J. Principles of critical care. New York: McGraw Hill Professional; 2015.

67. Atkinson PR, McAuley DJ, Kendall RJ, Abeyakoon O, Reid CG, Connolly J, et al. Abdominal and Cardiac Evaluation with Sonography in Shock (ACES): an approach by emergency physicians for the use of ultrasound in patients with undifferentiated hypotension. Emerg Med J: EMJ. 2009;26(2):87-91.

68. Perera P, Mailhot T, Riley D, Mandavia D. The RUSH exam: Rapid Ultrasound in SHock in the evaluation of the critically 111. Emerg Med Clin North Am. 2010;28(1):29-56. vii

69. Rose JS, Bair AE, Mandavia D, Kinser DJ. The UHP ultrasound protocol: a novel ultrasound approach to the empiric evaluation of the undifferentiated hypotensive patient. Am J Emerg Med. 2001;19(4):299-302.

70. Mok KL. Make it SIMPLE: enhanced shock management by focused cardiac ultrasound. J Intensive Care. 2016;4:51.

71. Arntfield R, Pace J, Hewak M, Thompson D. Focused transesophageal echocardiography by emergency physicians is feasible and clinically influential: observational results from a novel ultrasound program. J Emerg Med. 2016;50(2):286-94. 
72. Bernier-Jean A, Albert M, Shiloh AL, Eisen LA, Williamson D, Beaulieu Y. The diagnostic and therapeutic impact of point-of-care ultrasonography in the intensive care unit. J Intensive Care Med. 2017;32(3):197-203. Bernier et al demonstrated that with current use, FCCE changes both diagnosis $(25 \%)$ and management plans $(44 \%)$ among ICU patients.

73. Hwang HJ, Sohn IS, Kim WS, Hong GR, Choi EY, Rim SJ, et al. The clinical impact of bedside contrast echocardiography in intensive care settings: a Korean multicenter study. Korean Circ J. 2015;45(6):486-91.

74. Manno E, Navarra M, Faccio L, Motevallian M, Bertolaccini L, Mfochive A, et al. Deep impact of ultrasound in the intensive care unit: the "ICU-sound" protocol. Anesthesiology. 2012;117(4):801-9.

75. Stanko LK, Jacobsohn E, Tam JW, De Wet CJ, Avidan M. Transthoracic echocardiography: impact on diagnosis and management in tertiary care intensive care units. Anaesth Intensive Care. 2005;33(4):492-6.

76. Lang RM, Badano LP, Mor-Avi V, Afilalo J, Armstrong A, Ernande L, et al. Recommendations for cardiac chamber quantification by echocardiography in adults: an update from the American Society of Echocardiography and the European Association of Cardiovascular Imaging. Eur Heart J-Cardiovasc Imaging. 2015;16(3):233-71.

77. Gudmundsson P, Rydberg E, Winter R, Willenheimer R. Visually estimated left ventricular ejection fraction by echocardiography is closely correlated with formal quantitative methods. Int J Cardiol. 2005;101(2):209-12.

78. Shahgaldi K, Gudmundsson P, Manouras A, Brodin LA, Winter R. Visually estimated ejection fraction by two dimensional and triplane echocardiography is closely correlated with quantitative ejection fraction by real-time three dimensional echocardiography. Cardiovase Ultrasound. 2009;7:41.

79. Akinboboye O, Sumner J, Gopal A, King D, Shen Z, Bardfeld P, et al. Visual estimation of ejection fraction by two-dimensional echocardiography: the learning curve. Clin Cardiol. 1995;18(12): 726-9.

80. Unluer EE, Karagoz A, Akoglu H, Bayata S. Visual estimation of bedside echocardiographic ejection fraction by emergency physicians. West J Emerg Med. 2014;15(2):221-6.

81. Melamed R, Sprenkle MD, Ulstad VK, Herzog CA, Leatherman JW. Assessment of left ventricular function by intensivists using hand-held echocardiography. Chest. 2009;135(6):1416-20.

82. Krishnan S, Schmidt GA. Acute right ventricular dysfunction: real-time management with echocardiography. Chest. 2015;147(3):835-46

83. Jardin F, Dubourg O, Bourdarias JP. Echocardiographic pattern of acute cor pulmonale. Chest. 1997;111(1):209-17.

84. Ryan T, Petrovic O, Dillon JC, Feigenbaum H, Conley MJ, Armstrong WF. An echocardiographic index for separation of right ventricular volume and pressure overload. J Am Coll Cardiol. 1985;5(4):918-27.

85. Vieillard-Baron A, Prin S, Chergui K, Dubourg O, Jardin F. EchoDoppler demonstration of acute cor pulmonale at the bedside in the medical intensive care unit. Am J Respir Crit Care Med. 2002;166(10):1310-9.

86. Bova C, Greco F, Misuraca G, Serafini O, Crocco F, Greco A, et al. Diagnostic utility of echocardiography in patients with suspected pulmonary embolism. Am J Emerg Med. 2003;21(3): 180-3.

87. Miniati M, Monti S, Pratali L, Di Ricco G, Marini C, Formichi B, et al. Value of transthoracic echocardiography in the diagnosis of pulmonary embolism: results of a prospective study in unselected patients. Am J Med. 2001;110(7):528-35.

88. Steiner P, Lund GK, Debatin JF, Steiner D, Nienaber C, Nicolas V, et al. Acute pulmonary embolism: value of transthoracic and transesophageal echocardiography in comparison with helical CT. AJR Am J Roentgenol. 1996;167(4):931-6.

89. McConnell MV, Solomon SD, Rayan ME, Come PC, Goldhaber SZ, Lee RT. Regional right ventricular dysfunction detected by echocardiography in acute pulmonary embolism. Am J Cardiol. 1996;78(4):469-73.

90. Kurzyna M, Torbicki A, Pruszczyk P, Burakowska B, Fijalkowska A, Kober J, et al. Disturbed right ventricular ejection pattern as a new Doppler echocardiographic sign of acute pulmonary embolism. Am J Cardiol. 2002;90(5):507-11.

91. Casazza F, Bongarzoni A, Capozi A, Agostoni O. Regional right ventricular dysfunction in acute pulmonary embolism and right ventricular infarction. Eur J Echocardiogr. 2005;6(1):11-4.

92. Lodato JA, Ward RP, Lang RM. Echocardiographic predictors of pulmonary embolism in patients referred for helical CT. Echocardiogr (Mount Kisco, NY). 2008;25(6):584-90.

93. Pruszczyk P, Torbicki A, Kuch-Wocial A, Szulc M, Pacho R. Diagnostic value of transoesophageal echocardiography in suspected haemodynamically significant pulmonary embolism. Heart. 2001;85(6):628-34.

94. Wittlich N, Erbel R, Eichler A, Schuster S, Jakob H, Iversen S, et al. Detection of central pulmonary artery thromboemboli by transesophageal echocardiography in patients with severe pulmonary embolism. J Am Soc Echocardiogr: Off Publ Am Soc Echocardiogr. 1992;5(5):515-24.

95. Vieillard-Baron A, Qanadli SD, Antakly Y, Fourme T, Loubieres Y, Jardin F, et al. Transesophageal echocardiography for the diagnosis of pulmonary embolism with acute cor pulmonale: a comparison with radiological procedures. Intensive Care Med. 1998;24(5):429-33.

96. Nazerian P, Vanni S, Volpicelli G, Gigli C, Zanobetti M, Bartolucci M, et al. Accuracy of point-of-care multiorgan ultrasonography for the diagnosis of pulmonary embolism. Chest. 2014;145(5):950-7.

97. Ribeiro A, Lindmarker P, Juhlin-Dannfelt A, Johnsson H, Jorfeldt L. Echocardiography Doppler in pulmonary embolism: right ventricular dysfunction as a predictor of mortality rate. Am Heart J. 1997;134(3):479-87.

98. Kasper W, Konstantinides S, Geibel A, Tiede N, Krause T, Just H. Prognostic significance of right ventricular afterload stress detected by echocardiography in patients with clinically suspected pulmonary embolism. Heart. 1997;77(4):346-9.

99. Kucher N, Rossi E, De Rosa M, Goldhaber SZ. Prognostic role of echocardiography among patients with acute pulmonary embolism and a systolic arterial pressure of $90 \mathrm{~mm} \mathrm{Hg}$ or higher. Arch Intern Med. 2005;165(15):1777-81.

100. Grifoni S, Olivotto I, Cecchini P, Pieralli F, Camaiti A, Santoro G, et al. Short-term clinical outcome of patients with acute pulmonary embolism, normal blood pressure, and echocardiographic right ventricular dysfunction. Circulation. 2000;101(24):2817-22.

101. Jerjes-Sanchez C, Ramírez-Rivera A, de Lourdes García M, Arriaga-Nava R, Valencia S, Rosado-Buzzo A, et al. Streptokinase and heparin versus heparin alone in massive pulmonary embolism: a randomized controlled trial. J Thromb Thrombolysis. 1995;2(3):227-9.

102. Meyer G, Vicaut E, Danays T, Agnelli G, Becattini C, BeyerWestendorf $\mathrm{J}$, et al. Fibrinolysis for patients with intermediaterisk pulmonary embolism. N Engl J Med. 2014;370(15):1402-11.

103. Chatterjee S, Chakraborty A, Weinberg I, Kadakia M, Wilensky RL, Sardar P, et al. Thrombolysis for pulmonary embolism and risk of all-cause mortality, major bleeding, and intracranial hemorrhage: a meta-analysis. JAMA. 2014;311(23):2414-21.

104. Brown SM, Pittman J, Miller Iii RR, Horton KD, Markewitz B, Hirshberg E, et al. Right and left heart failure in severe H1N1 influenza A infection. Eur Respir J. 2011;37(1):112-8. 
105. Boissier F, Katsahian S, Razazi K, Thille AW, Roche-Campo F, Leon R, et al. Prevalence and prognosis of cor pulmonale during protective ventilation for acute respiratory distress syndrome. Intensive Care Med. 2013;39(10):1725-33.

106. Mekontso Dessap A, Boissier F, Charron C, Begot E, Repesse X, Legras A, et al. Acute cor pulmonale during protective ventilation for acute respiratory distress syndrome: prevalence, predictors, and clinical impact. Intensive Care Med. 2016;42(5):862-70.

107. Lheritier G, Legras A, Caille A, Lherm T, Mathonnet A, Frat JP, et al. Prevalence and prognostic value of acute cor pulmonale and patent foramen ovale in ventilated patients with early acute respiratory distress syndrome: a multicenter study. Intensive Care Med. 2013;39(10):1734-42.

108. Vieillard-Baron A, Price LC, Matthay MA. Acute cor pulmonale in ARDS. Intensive Care Med. 2013;39(10):1836-8.

109. McCanny P, Colreavy F. Echocardiographic approach to cardiac tamponade in critically ill patients. J Crit Care. 2017;39:271-7.

110. Klein AL, Abbara S, Agler DA, Appleton CP, Asher CR, Hoit B, et al. American Society of Echocardiography clinical recommendations for multimodality cardiovascular imaging of patients with pericardial disease: endorsed by the Society for Cardiovascular Magnetic Resonance and Society of Cardiovascular Computed Tomography. J Am Soc Echocardiogr : Off Publ Am Soc Echocardiogr. 2013;26(9):965-1012. e15

111. McLean AS. Echocardiography in shock management. Critical Care (London, England). 2016;20:275.

112. Lanspa MJ, Pittman JE, Hirshberg EL, Wilson EL, Olsen T, Brown SM, et al. Association of left ventricular longitudinal strain with central venous oxygen saturation and serum lactate in patients with early severe sepsis and septic shock. Critical Care (London, England). 2015;19:304. While strain is known to be useful in the identification of myocardial ischemia and fibrosis, this paper suggests that strain may also be a marker of acute cardiac failure related to sepsis.

113. Landesberg G, Jaffe AS, Gilon D, Levin PD, Goodman S, AbuBaih A, et al. Troponin elevation in severe sepsis and septic shock: the role of left ventricular diastolic dysfunction and right ventricular dilatation*. Crit Care Med. 2014;42(4):790-800.

114. Orde SR, Pulido JN, Masaki M, Gillespie S, Spoon JN, Kane GC, et al. Outcome prediction in sepsis: speckle tracking echocardiography based assessment of myocardial function. Critical Care (London, England). 2014;18(4):R149.

115. Singh RK, Kumar S, Nadig S, Baronia AK, Poddar B, Azim A, et al. Right heart in septic shock: prospective observational study. J Intensive Care. 2016;4:38.

116. Database: clinicaltrials.gov. Echo vs EGDT in severe sepsis and septic shock [Internet]. Accessed 07/12/2017.

117. Denys BG, Uretsky BF, Reddy PS. Ultrasound-assisted cannulation of the internal jugular vein. A prospective comparison to the external landmark-guided technique. Circulation. 1993;87(5):1557-62.

118. Karakitsos D, Labropoulos N, De Groot E, Patrianakos AP, Kouraklis G, Poularas J, et al. Real-time ultrasound-guided catheterisation of the internal jugular vein: a prospective comparison with the landmark technique in critical care patients. Crit Care. 2006;10(6):R162.

119. Rupp SM, Apfelbaum JL, Blitt C, Caplan RA, Connis RT, Domino KB, et al. Practice guidelines for central venous access: a report by the American Society of Anesthesiologists Task Force on Central Venous Access. Anesthesiology. 2012;116(3):539.

120. Chou EH, Dickman E, Tsou PY, Tessaro M, Tsai YM, Ma MH, et al. Ultrasonography for confirmation of endotracheal tube placement: a systematic review and meta-analysis. Resuscitation. 2015;90:97-103.

121. Fu J, Tan CO, Weinberg L, Story DA. Use of transthoracic echocardiography to confirm pulmonary artery catheter placement. Anaesth Intensive Care. 2015;43(1):133-4.
122. Weekes AJ, Johnson DA, Keller SM, Efune B, Carey C, Rozario NL, et al. Central vascular catheter placement evaluation using saline flush and bedside echocardiography. Acad Emerg Med Off J Soc Acad Emerg Med. 2014;21(1):65-72.

123. Hirshberg EL, Kuttler K, Lanspa MJ, Brown SM, Grissom CK. Ultrasound Confirmation Of Central Venous Catheter Placement Could Reduce Hospital Costs. D22 quality improvement: admission to discharge. Am J Respir Crit Care Med. 2014;189:A5450-A.

124. Raman D, Sharma M, Moghekar A, Wang X, Hatipoglu U. Utilization of thoracic ultrasound for confirmation of central venous catheter placement and exclusion of pneumothorax: a novel technique in real-time application. J Intensive Care Med. 2017; https://doi.org/10.1177/0885066617705839. Use of bedside ultrasonography to confirm CVC placement expedites the time between catheter placement and use and can eliminate the need for a chest $x$-ray which exposes the patient to ionizing radiation.

125. Link MS, Berkow LC, Kudenchuk PJ, Halperin HR, Hess EP, Moitra VK, et al. Part 7: adult advanced cardiovascular life support: 2015 American Heart Association Guidelines Update for Cardiopulmonary Resuscitation and Emergency Cardiovascular Care. Circulation. 2015;132(18 Suppl 2):S444-64.

126. Breitkreutz R, Price S, Steiger HV, Seeger FH, Ilper H, Ackermann H, et al. Focused echocardiographic evaluation in life support and peri-resuscitation of emergency patients: a prospective trial. Resuscitation. 2010;81(11):1527-33.

127. Chardoli M, Heidari F, Rabiee H, Sharif-Alhoseini M, Shokoohi H, Rahimi-Movaghar V. Echocardiography integrated ACLS protocol versus conventional cardiopulmonary resuscitation in patients with pulseless electrical activity cardiac arrest. Chin J Traumatol = Zhonghua chuang shang za zhi. 2012;15(5):284-7.

128. Zengin S, Yavuz E, Al B, Cindoruk S, Altunbas G, Gumusboga H, et al. Benefits of cardiac sonography performed by a non-expert sonographer in patients with non-traumatic cardiopulmonary arrest. Resuscitation. 2016;102:105-9.

129. Prosen G, Krizmaric M, Zavrsnik J, Grmec S. Impact of modified treatment in echocardiographically confirmed pseudo-pulseless electrical activity in out-of-hospital cardiac arrest patients with constant end-tidal carbon dioxide pressure during compression pauses. J Int Med Res. 2010;38(4):1458-67.

130. Gaspari R, Weekes A, Adhikari S, Noble VE, Nomura JT, Theodoro D, et al. Emergency department point-of-care ultrasound in out-of-hospital and in-ED cardiac arrest. Resuscitation. 2016;109:33-9. This is the largest cohort study to date inspecting the relevance of FCCE in cardiac arrest in the emergency department.

131. Tsou PY, Kurbedin J, Chen YS, Chou EH, Lee MG, Lee MC, et al. Accuracy of point-of-care focused echocardiography in predicting outcome of resuscitation in cardiac arrest patients: a systematic review and meta-analysis. Resuscitation. 2017;114:92-9.

132. Breitkreutz R, Walcher F, Seeger FH. Focused echocardiographic evaluation in resuscitation management: concept of an advanced life support-conformed algorithm. Crit Care Med. 2007;35(5 Suppl):S150-61.

133. Lichtenstein D, Malbrain ML. Critical care ultrasound in cardiac arrest. Technological requirements for performing the SESAMEprotocol-a holistic approach. Anaesthesiol Intensiv Therapy. 2015;47(5):471-81.

134. Testa A, Cibinel GA, Portale G, Forte P, Giannuzzi R, Pignataro $\mathrm{G}$, et al. The proposal of an integrated ultrasonographic approach into the ALS algorithm for cardiac arrest: the PEA protocol. Eur Rev Med Pharmacol Sci. 2010;14(2):77-88.

135. Christenson J, Andrusiek D, Everson-Stewart S, Kudenchuk P, Hostler D, Powell J, et al. Chest compression fraction determines survival in patients with out-of-hospital ventricular fibrillation. Circulation. 2009;120(13):1241-7. 